\title{
The influence of window size on remote sensing-based prediction of forest structural variables
}

\author{
Ulas Yunus Ozkan ${ }^{*}$ and Tufan Demirel
}

\begin{abstract}
Background: Determining the appropriate window size is a critical step in the estimation process of stand structural variables based on remote sensing data. Because the value of the reference laser and image metrics that affect the quality of the prediction model depends on window size. However, suitable window sizes are usually determined by trial and error. There are a limited number of published studies evaluating appropriate window sizes for different remote sensing data. This research investigated the effect of window size on predicting forest structural variables using airborne LiDAR data, digital aerial image and WorldView-3 satellite image.

Results: In the WorldView-3 and digital aerial image, significant differences were observed in the prediction accuracies of the structural variables according to different window sizes. For the estimation based on WorldView-3 in black pine stands, the optimal window sizes for stem number $(\mathrm{N})$, volume $(\mathrm{V})$, basal area $(\mathrm{BA})$ and mean height $(\mathrm{H})$ were determined as $1000 \mathrm{~m}^{2}, 100 \mathrm{~m}^{2}, 100 \mathrm{~m}^{2}$ and $600 \mathrm{~m}^{2}$, respectively. In oak stands, the $R^{2}$ values of each moving window size were almost identical for $\mathrm{N}$ and BA. The optimal window size was $400 \mathrm{~m}^{2}$ for $\mathrm{V}$ and $600 \mathrm{~m}^{2}$ for $\mathrm{H}$. For the estimation based on aerial image in black pine stands, the $800 \mathrm{~m}^{2}$ window size was optimal for $\mathrm{N}$ and $\mathrm{H}$, the $600 \mathrm{~m}^{2}$ window size was optimal for $V$ and the $1000 \mathrm{~m}^{2}$ window size was optimal for BA. In the oak stands, the optimal window sizes for $\mathrm{N}, \mathrm{V}, \mathrm{BA}$ and $\mathrm{H}$ were determined as $1000 \mathrm{~m}^{2}, 100 \mathrm{~m}^{2}, 100 \mathrm{~m}^{2}$ and $600 \mathrm{~m}^{2}$, respectively. The optimal window sizes may need to be scaled up or down to match the stand canopy components. In the LiDAR data, the $R^{2}$ values of each window size were almost identical for all variables of the black pine and the oak stands.

Conclusion: This study illustrated that the window size has an effect on the prediction accuracy in estimating forest structural variables based on remote sensing data. Moreover, the results showed that the optimal window size for forest structural variables varies according to remote sensing data and tree species composition.
\end{abstract}

Keywords: Optimal window size, Random forest, WorldView-3, Digital aerial image, LiDAR

\section{Background}

Forests are important ecosystems thanks to their many services, such as soil conservation, improving air and water quality, decreasing noise pollution, carbon storage (Lee et al. 2010). For sustainable management of these ecosystems, data on horizontal and vertical forest structure are required (Pascual et al. 2008; Koch et al. 2009)

\footnotetext{
*Correspondence: uozkan@istanbul.edu.tr

Department of Forest Management, Faculty of Forestry, Istanbul University-Cerrahpaşa, 34473 Istanbul, Turkey
}

because the forest structure has an important effect on ecosystem services (García et al. 2018; Kaushal and Baishya 2021). Forest structural data are traditionally provided from field data of limited spatial extent. However, traditional methods involving the forest inventories process, which require labor-intensive field surveys, are time consuming and expensive (Kwak et al. 2007; Joshi et al. 2015; García et al. 2018). Remote sensing data has been used as an auxiliary data source in forest inventory since early days of remote sensing (Kayitakire et al. 2006). Stand structural variables such as crown canopy, 
species composition, stem density and basal area can be estimated using remote sensing data on the forest stand level. Therefore, the remote sensing data have great potential to reduce inventory cost and improve estimation accuracy (Steinmann et al. 2013).

Aerial photographs are oldest remote sensing data used in forest inventory and have still an important role in forest planning (Morgan et al. 2010; Ozkan and Demirel 2018). Over the last 30 years, there has been a transition from analogous photogrammetry to digital photogrammetry as analogous aerial photographs are replaced with digital aerial images (Balenovic et al. 2015). In addition to high spatial resolution, RGBIR (Red, Green, Blue, Infrared) bands and digital data flow of digital aerial images provide a great advantage in estimating forest stand parameters and producing forest stand maps (Hájek 2008). Current digital aerial cameras such as UltraCamX can provide digital images of very high (30 to $10 \mathrm{~cm}$ ) spatial resolution (Balenović et al. 2015). Satellite images with very high spatial resolution are a cost-effective alternative source to aerial photographs. Satellite images have important advantages such as broad spatial coverage and temporally high frequency (García et al. 2018; Ustin and Middleton 2021). Numerous methods have been developed using image features such as reflectance values, texture features and vegetation indices derived from satellite images to estimate forest structural parameters (Ozdemir and Karnieli 2011; Ozkan et al. 2016). LiDAR (Light Detection and Ranging) data, an active remote sensing technology, has significant potential for the prediction of forest structural variables. Unlike optical sensors, LiDAR has the ability to provide information about both horizontal and vertical structural features of forests (Lim et al. 2003; Hu et al. 2014). Therefore, LiDAR data can better capture the three-dimensional (3-D) structure of forest canopies than passive optical sensors, given their ability to penetrate the canopy to different depths (Zald et al. 2014; García et al. 2018). LiDAR which is among the available remote sensing data is a powerful data source for measuring and predicting forest structural features (Joshi et al. 2015; Zeybek and Vatandaslar 2021).

Due to these advantages, numerous studies have been conducted to evaluate the potential of each remote sensing data in the forest inventory. The studies were first carried out based on visual interpretation. In stand volume estimates based on the visual interpretation of the aerial photograph, the relative error has been reported as between 14 and $45 \%$ and in the prediction based on the satellite image interpretation, the corresponding error has been reported as between 20 and 70\% (Hyyppa et al. 2001). The evolving expectations on the time, accuracy and cost effectiveness of forest inventory studies have led visual interpretation to be replaced by semi-automatic and automatic techniques over time (Hájek 2008). Tuominen and Pekkarinen (2005) evaluated the estimation possibilities of some forest structural parameters (diameter at breast height, height, basal area, and volume) using digital aerial imagery. As a result of the study, it has been revealed that forest structural parameters are highly correlated with image features and can be predicted with high accuracy. In another study conducted by Ozkan and Demirel (2018) on pure red pine stands, it was revealed that stand parameters can be predicted using spectral and texture features derived from digital aerial images. In the study performed by Ozdemir and Karnieli (2011) it was stated that there were significant correlations between image texture features and forest structural parameters. Günlü et al. (2021) evaluated the potential of WorldView-2 satellite imagery to estimate some stand parameters using different modeling techniques in pure Crimean pine stands. The results of the study showed that the developed prediction models are useful for the estimation of stand parameters. Kanja and Karahalil (2019) modeled some stand parameters using airborne LiDAR data in pure red pine stands. The developed models revealed that stand parameters can be estimated with high accuracy using LiDAR metrics.

The prediction accuracy of structural variables varies considerably depending on the spatial resolution of image, sampling window size, laser and image metrics (Iovan et al. 2008; Zenner et al. 2009; Castillo-Santiago et al. 2010; Steinmann et al. 2013; Meng et al. 2016). Several studies have shown that the sample plot size is an important factor for the accuracy of forest inventory (Hájek 2008; García et al. 2018; Robinson et al. 2013). Ruiz et al. 2014 pointed out that the larger sample plot sizes do not significantly increase the estimation accuracy and it should have a minimum size of $500-600 \mathrm{~m}^{2}$ for volume estimation. Likewise, sampling window size affects the estimation accuracy of models because the value of the reference laser and image metrics that affect the prediction model quality, depends on sampling window size (Castillo-Santiago et al. 2010; Steinmann et al. 2013; Meng et al. 2016). While a small window size increases the noise content in the image, too large window size cannot effectively extract the information. In addition, a larger window size means more processing time (Amini and Sumantyo 2009; Meng et al. 2016). Therefore, it is a critical step to determine the optimal window size that matches the forest canopy components, depending on the image spatial resolution.

Several studies have shown the impact of window size on the estimation accuracy of forest structural variables using remote sensing data. Holopainen and Wang (1998) stated that the optimal window size depends on forest stand class, spectral band and image scale. They also 
stated that $20 \times 20 \mathrm{~m}$ window size is the near-optimal window size for feature extraction from aerial photograph in forest inventory. Kayitakire et al. (2006) investigated the estimation of forest structural variables by means of texture features from IKONOS-2. It was stated that stand age is best explained by window size of $15 \times 15$ pixels, density by window size of $5 \times 5$ pixels, height by window size of $15 \times 15$ pixels and basal area by window size of $25 \times 25$. Rich et al. (2010) determined that the patterns in image texture of IKONOS satellite image did not change from 25 to $225 \mathrm{~m}^{2}$ window size. In the study conducted by Tonolli et al. (2011), the accuracy of the estimation of tree stem volume was assessed using LiDAR data. The study results revealed that optimal cell size is $40 \times 40 \mathrm{~m}$. Steinmann et al. (2013) stated that the window size of $25 \times 25 \mathrm{~m}$ is optimal for estimating the forest growing stock volume using LiDAR data and aerial images. Meng et al. (2016) tested seven window sizes (from $3 \times 3$ to $15 \times 15$ pixels) to estimate forest structure from the SPOT-5 satellite image. To determine the optimum window size, they calculated the Pearson correlation coefficient of texture statistics with biomass and stated that $9 \times 9$ pixel window size is the minimum window size that provides the highest correlation coefficient. Zhao et al. (2018) identified the optimal window size for estimating canopy cover using QuickBird multispectral and panchromatic images. Window size of $15 \times 15$ pixels for panchromatic image and window size of $9 \times 9$ pixels for multispectral image were chosen as the optimal window size. Zhou et al. (2020) developed growing stock volume estimation models using $3 \times 3,5 \times 5,7 \times 7,9 \times 9$, $11 \times 11,13 \times 13$, and $15 \times 15$ window sizes. Spectral vegetation indices (SVIs), texture parameters and their combinations obtained from SPOT-6 satellite imagery were used in the study. They stated that $3 \times 3$ or $5 \times 5$ window sizes gave better results than the others. Günlü et al. (2021) tested 12 different window sizes (from $3 \times 3$ to $25 \times 25$ ) for the estimation of stand volume, basal area, number of trees and aboveground biomass from WorldView-2 satellite image. They emphasized that window sizes of $17 \times 17,19 \times 19$ and $23 \times 23$ gave the best results. According to these studies, optimal window size depends on remote sensing data and forest structural variables to be estimated. However, this issue has not been evaluated sufficiently yet. Further studies are needed to determine the optimal window sizes for estimation of forest structure features using remote sensing data.

The objective of this research is to investigate the effects of window size on estimation accuracy of forest structural variables based on LiDAR data, digital aerial image and WorldView-3 satellite image. More specifically, (i) sampling windows of different sizes (200, 400, 600,800 and $1000 \mathrm{~m}^{2}$ ) were developed from remote sensing data; (ii) estimation models were developed based on reference laser and image metrics extracted from image windows were developed; (iii) the effect of window size on accuracy of the models was analyzed and the optimal window sizes were determined for estimating forest structural variables.

\section{Materials and methods Study area}

The study area is located on the Thrace side of the Marmara region of Turkey $\left(41^{\circ} 09^{\prime} 15^{\prime \prime}-41^{\circ} 11^{\prime} 01^{\prime \prime} \mathrm{N}\right.$ and $28^{\circ}$ $59^{\prime} 17^{\prime \prime}-29^{\circ} 02^{\prime} 25^{\prime \prime}$ E) (Fig. 1). It has an elevation ranging from 10 to $237 \mathrm{~m}$ above sea level. In the study area with a total area of 2172 hectares, the forest area cover constitutes $88 \%$ of the total area. Red pine, Black pine, Stone pine, Maritime pine, Oak, Chestnut, Beech, Linden, and Hornbeam species constitute a large number of stands in pure or mixed form. Most of the forest area consists of broadleaf stands which are dominated by oak species. Among the coniferous species, Black pine and Maritime pine are the dominant species. In addition, stand management regime of the forest is even-aged. Detailed information for the research area was presented by Ozkan et al. (2020).

\section{Field reference data}

A field survey was performed between June and August 2018 on the sample plots. A total of 45 samples were randomly selected from pure black pine and oak stands within a study area of 2172 hectares using stand maps produced based on the combination of aerial photograph and forest inventory data in the forest management plan. These stands were visited by a field crew and sample plots were established and the central points were located using GNSS/CORS GPS in each stand. The accuracy of the positioning was approximately $0.25 \mathrm{~m}$. The sample plots were consisted of six concentric circles with an area of $100 \mathrm{~m}^{2}$ to $1000 \mathrm{~m}^{2}$ (Fig. 2a). All trees with a diameter at breast height $(\mathrm{DBH}) \geq 8 \mathrm{~cm}$ were recorded within each of the sample plots of different sizes and their heights measured with a Haglöf Vertex VL5 Laser field measuring instrument. For the sample plot, stem number $(\mathrm{N})$, basal area $\left(\mathrm{BA}, \mathrm{m}^{2}\right)$, volume $\left(\mathrm{V}, \mathrm{m}^{3}\right)$ and mean height $(\mathrm{H}, \mathrm{m})$ parameters were determined. Basal area was calculated from the diameter measurements of all trees. These values that calculated for each tree in the sample plot were summed. Volume of each tree was computed based on species-specific equations obtained from the forest management plan. Total plot volume was calculated as the sum of the individual tree volumes. The mean height was determined as the arithmetic mean height of 


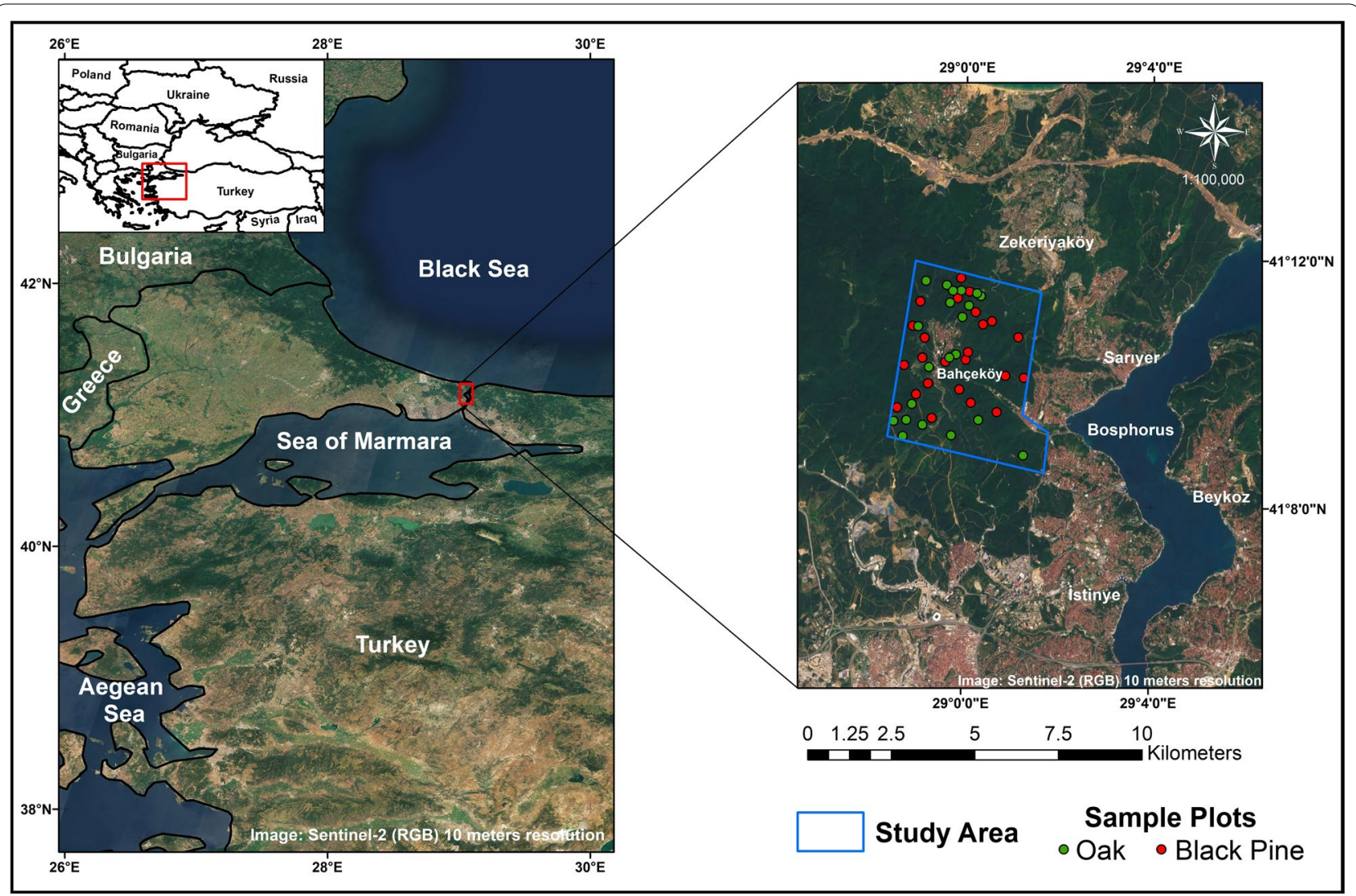

Fig. 1 Study area

all measured trees in the sample plot. The descriptive statistics of the ground truth data are depicted in Table 1.

\section{Remote sensing data and processing}

The remote sensing data set included airborne and satellite data: digital aerial imagery, LiDAR and WorldView-3. High point density airborne LiDAR data for the study area were acquired on 22 July 2018, using the LMS-Q680i laser scanner system at a nominal altitude of $720 \mathrm{~m}$ above ground level. The system operated at $400 \mathrm{kHz}$ laser pulse repetition rate and a wavelength of $1550 \mathrm{~nm}$. While the point density varied throughout the study area, the minimum point density was 12 points $/ \mathrm{m}^{2}$. Multiple turns were recorded as well as intensity values for each pulse. The maximum scan angles were $\pm 20^{\circ}$ off-nadir. All artificial objects such as buildings, power lines, base stations have been removed from the raw LiDAR point cloud data using Global Mapper software. After this process, the LiDAR point cloud was divided into two classes, ground and vegetation, to obtain a normalized point cloud (NPC). While the last return points were classified as ground points, points other than ground class were assigned to the vegetation class using the NDVI
(Normalized Difference Vegetation Index) image. The digital terrain model (DTM), as a representation of the ground area, was generated with the TIN (triangulated irregular networks) from the ground class points (Kwak et al. 2007). After obtaining the DTM, the relative height of each point was determined as the difference between the point's height and the terrain surface height. Therefore, the NPC representing the height above ground level was obtained. Finally, to eliminate the effects of objects such as shrubs and rocks, the vegetation height threshold (average $2 \mathrm{~m}$ ) was applied to the NPC value, which represents the tree canopy height in forest areas (Næsset 2002).

Aerial images were acquired on May 2015 using UltraCamX (Microsoft, Vexcel Imaging $\mathrm{GmbH}$ ) digital aerial camera. The camera has $7.2 \mu \mathrm{m}$ physical sensor pixel size. Aerial images are totally comprised of four bands which are Red (580-700 nm), Green (480-630 nm), Blue $(410-540 \mathrm{~nm})$ and Infrared $(690-1000 \mathrm{~nm})$ bands. These images were taken as stereo from altitude of $4200 \mathrm{~m}$ above ground level with 70\% forward and 30\% side overlap. For each raw stereo image pairs, geometric calibration and radiometric correction utilized in ERDAS LPS 


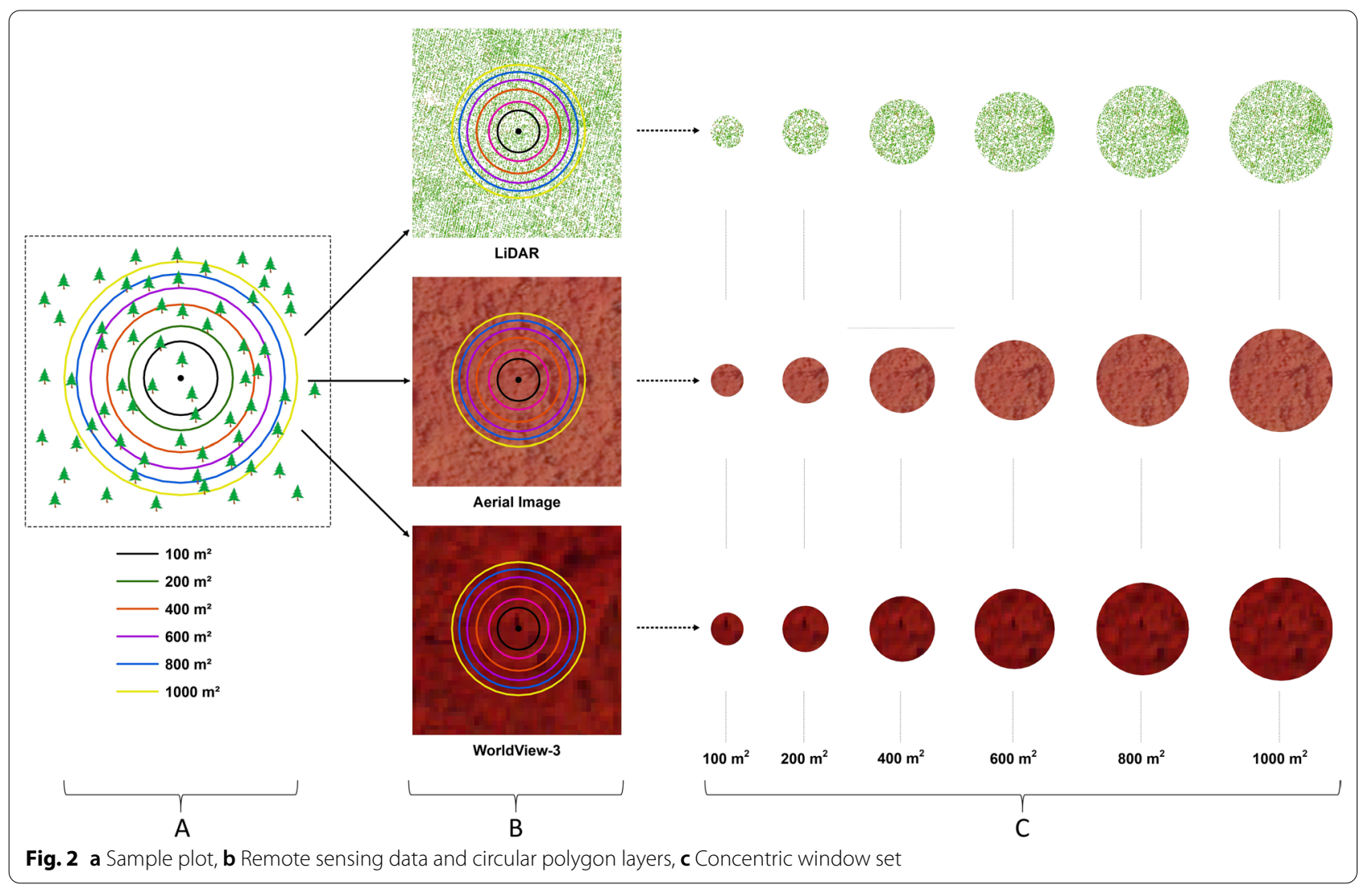

Table 1 Descriptive statistics of the forest structural variables in sample plots

\begin{tabular}{llrrrr}
\hline Stand & Variables & Minimum & Maximum & Mean & SD \\
\hline Black pine & $\mathrm{N}\left(\mathrm{ha}^{-1}\right)$ & 525 & 1350 & 959 & 240 \\
& $\mathrm{BA}\left(\mathrm{m}^{2} \mathrm{ha}^{-1}\right)$ & 27,36 & 49,28 & 37,91 & 6,33 \\
& $\mathrm{~V}\left(\mathrm{~m}^{3} \mathrm{ha}^{-1}\right)$ & 144,60 & 451,66 & 226,63 & 68,38 \\
& $\mathrm{H}(\mathrm{m})$ & 9,50 & 20,30 & 11,97 & 2,32 \\
Oak & $\mathrm{N}\left(\mathrm{ha}^{-1}\right)$ & 550 & 1700 & 1115 & 286 \\
& $\mathrm{BA}\left(\mathrm{m}^{2} \mathrm{ha}^{-1}\right)$ & 18,74 & 37,35 & 24,86 & 3,73 \\
& $\mathrm{~V}\left(\mathrm{~m}^{3} \mathrm{ha}^{-1}\right)$ & 150,25 & 366,58 & 223,16 & 50,60 \\
& $\mathrm{H}(\mathrm{m})$ & 13,00 & 18,00 & 15,33 & 1,32 \\
\hline
\end{tabular}

(Hexagon Geospatial) software using interior (focal length, coordinates of the principal point) and exterior (position and rotation of the camera) orientation parameters.

WorldView-3 multispectral image was acquired over the study area on June 2018 with 1.24 m spatial resolution. The multispectral image had four bands, including blue $(0.45-0.51 \mu \mathrm{m})$, green $(0.51-0.58 \mu \mathrm{m})$, red $(0.63-0.69 \mu \mathrm{m})$ and near-infrared $(0.78-0.92 \mu \mathrm{m})$ bands. Atmospheric correction was carried out using the physical model based approach as implemented in ATCOR (PCI Geomatics 2017). Solar Zenith and Azimuth values of the satellite image, radiometric calibration values for each spectrum gathered from WorldView-3's metadata and DTM generated from the LiDAR data were used to create a fog and aerosol-free satellite image, and object reflectance values were obtained using PCI Geomatica software. After this atmospheric correction process, the orthorectification was performed using DTM and ground control points. To provide more detailed data on vegetation-covered areas, NDVI, the most commonly used vegetation index, was produced using NearIR-1 and Red bands of WorldView-3 (Cho et al. 2009).

\section{Predictor variables}

The laser and image metrics corresponding to the sample plots were extracted from three different remote sensing data. These metrics that were used as predictor variables were obtained from circular image windows with different moving window sizes centered on each sample plot. For this, first of all, the center points of the ground sample plots were spatially registered on remote sensing data by means of GIS. Then a total of six concentric circular polygon layers of different sizes corresponding to ground sample areas were created (Fig. 2a). Finally, these 
polygon layers were cut and the image windows with the same center points of 100, 200,400,600, 800 and 1000 $\mathrm{m}^{2}$ were created separately for LiDAR, aerial image and WorldView-3 data (Fig. 2b). Thus, a total of 45 concentric window sets were created which of six image windows with a size of $100 \mathrm{~m}^{2}$ to $1000 \mathrm{~m}^{2}$ (Fig. 2c). Each laser and image metric was obtained by averaging over these image windows.

LiDAR metrics, that be used as potential variables in predictive models of forest structural variables, were computed for each LiDAR window. LiDAR metrics were derived from the normalized point clouds of the LiDAR windows using trial version of the LiDAR360 software. In this study, a total of 102 LiDAR metrics (LiDAR360 2018) were extracted from LiDAR pulses using two basic properties of LiDAR data: "Height Metrics" and "Density Metrics".

Spectral and textural metrics were extracted from aerial images and WorldView-3 satellite image by averaging their values within image windows. For each image window, the following spectral features were calculated to explain potential variation in the forest structural variables: mean, standard deviation, skewness and NDVI values. The texture properties were determined according to the Gray Level Co-occurrence Matrix (GLCM) (Haralick et al. 1973). GLCM is widely utilized to describe the textural properties in remote sensing studies (Kayitakire et al. 2006; Maltamo et al., 2006; Shamsoddini et al., 2013; Ozdemir and Donoghue 2013; Ozkan et al. 2016,2020; Meng 2016; Zhao et al. 2018). There are many texture properties defined by GLCM in three main groups as Contrast, Orderliness and Descriptive (Ozdemir and Karnieli 2011). These properties can be affected by three main factors: (a) spatial resolution and spectral characteristics of remote sensing image; (b) characteristics of the sensed objects (dimension, shape, and spatial distribution); and (c) window size and environmental conditions (Kayitakire et al. 2006; Maltamo et al. 2006; Shamsoddini et al. 2013). In addition, it is difficult to determine the best properties (Shamsoddini et al. 2013). Hence, all GLCM properties for each window size on remote sensing data were derived using eCognition software.

\section{Model construction and validation}

The Random Forest algorithm implemented in the "RandomForest" package within demo version of Addinsoft XLStat software was used to model the relationships between the image features extracted remote sensing data and forest structural parameters. The Random Forest method (RF), which was proposed by Breiman (2001), is an ensemble-learning algorithm that combines a large set of regression trees and this algorithm can reduce the overfitting of models. Previous studies have revealed that the RF algorithm has a high prediction accuracy (Zhao et al. 2018; Gao et al. 2019). Therefore, this application has achieved broad popularity lately.

While generating decision trees in the RF algorithm, there are two basic parameters that must be determined by user. These are the number of decision trees $\left(N_{\text {tree }}\right)$ to be produced and the number of variables $\left(M_{\text {try }}\right)$ to be tested each time. Since the RF algorithm is computationally efficient, the $N_{\text {tree }}$ can be kept as large as possible (Guan et al. 2013). In most of the studies, $N_{\text {tree }}$ value is determined as 500 which is default value of algorithm, since errors are fixed until the number of decision trees reaches 500. In addition, the $M_{\text {try }}$ parameter is usually determined to be $1 / 3$ of the number of explanatory variables for regression (Liaw et al. 2002). Explanatory variables are selected automatically in RF algorithm for regression. So that there is no need to select any explanatory variables before modeling.

In the study, after deciding on the best prediction model for forest structural parameters, the prediction error of the final model was estimated by leave-one-out cross-validation method. This method is a suitable validation method when a limited number of data is available for validation (Shamsoddini et al. 2013). In this method, for each forest parameters, one of the sample plots was eliminated from data set at a time and a model was developed using $n-1$ remaining plots. The dependent variables were then estimated for the removed sample plot. The procedure was repeated for each sample plot. Finally, the coefficient of determination $\left(R^{2}\right)$, and the root mean square error (RMSE) values between observed and predicted forest structural parameters were calculated to assess the overall accuracy of the fitted models.

\section{Results}

Using the random forest regression analysis, several prediction models were developed for forest structural variables. All models were statistically significant $(p<0.01)$. Table 2 and Fig. 3 show the performance of different window sizes for prediction of structural variables in the Black pine stands. In the Black pine stands, it was observed that significant differences between image windows in the estimation accuracy of forest structural variables. Forest structural variables were estimated with $R^{2}$ ranging from $0.70\left(\mathrm{H}\right.$, window size of $\left.1000 \mathrm{~m}^{2}\right)$ to 0.86 $\left(\mathrm{N}\right.$, window size of $\left.1000 \mathrm{~m}^{2}\right)$ using features derived from WorldView-3 satellite image. The $100 \mathrm{~m}^{2}$ window size performed better for $\mathrm{V}$ and $\mathrm{BA}\left(R^{2}=0.79\right.$ and 87 , respectively). The $1000 \mathrm{~m}^{2}$ window size provided the highest accuracy for $\mathrm{N}\left(R^{2}=0.86\right)$. For $\mathrm{H}, 600 \mathrm{~m}^{2}$ window size performed relatively better $\left(R^{2}=0.75\right)$. The prediction accuracy of forest structural variables varied between 
Table 2 Prediction results of the forest structural variables according to different window sizes (Black pine stands)

\begin{tabular}{|c|c|c|c|c|c|c|c|c|c|c|}
\hline \multirow{2}{*}{$\begin{array}{l}\text { Forest } \\
\text { variables }\end{array}$} & \multirow[t]{2}{*}{ Window size } & \multicolumn{3}{|c|}{ WorldView-3 } & \multicolumn{3}{|c|}{ Aerial image } & \multicolumn{3}{|c|}{ LiDAR } \\
\hline & & $R^{2}$ & RMSE & RMSE\% & $R^{2}$ & RMSE & RMSE\% & $R^{2}$ & RMSE & RMSE\% \\
\hline \multirow[t]{6}{*}{ N } & 100 & 0.78 & 109.37 & 11.40 & 0.80 & 103.59 & 10.80 & 0.84 & 94.75 & 9.87 \\
\hline & 200 & 0.73 & 120.92 & 12.60 & 0.80 & 105.55 & 11.00 & 0.84 & 93.23 & 9.72 \\
\hline & 400 & 0.79 & 108.45 & 11.30 & 0.84 & 93.90 & 9.79 & 0.83 & 96.97 & 10.11 \\
\hline & 600 & 0.80 & 103.79 & 10.82 & 0.86 & 87.72 & 9.14 & 0.83 & 95.60 & 9.96 \\
\hline & 800 & 0.82 & 100.33 & 10.46 & 0.88 & 82.68 & 8.62 & 0.84 & 94.79 & 9.88 \\
\hline & 1000 & 0.86 & 87.24 & 9.09 & 0.83 & 95.31 & 9.93 & 0.84 & 94.57 & 9.86 \\
\hline \multirow[t]{6}{*}{ V } & 100 & 0.79 & 30.50 & 13.46 & 0.77 & 31.30 & 13.81 & 0.76 & 32.62 & 14.39 \\
\hline & 200 & 0.75 & 33.27 & 14.68 & 0.75 & 33.28 & 14.69 & 0.78 & 31.21 & 13.77 \\
\hline & 400 & 0.74 & 33.84 & 14.93 & 0.74 & 33.97 & 14.99 & 0.79 & 30.51 & 13.46 \\
\hline & 600 & 0.77 & 32.24 & 14.23 & 0.78 & 31.36 & 13.84 & 0.79 & 30.83 & 13.60 \\
\hline & 800 & 0.77 & 31.78 & 14.02 & 0.75 & 33.53 & 14.80 & 0.79 & 31.10 & 13.72 \\
\hline & 1000 & 0.78 & 31.63 & 13.95 & 0.76 & 32.53 & 14.36 & 0.77 & 31.72 & 13.99 \\
\hline \multirow[t]{6}{*}{ BA } & 100 & 0.87 & 2.19 & 5.78 & 0.82 & 2.64 & 6.97 & 0.80 & 2.78 & 7.33 \\
\hline & 200 & 0.82 & 2.62 & 6.92 & 0.76 & 3.01 & 7.94 & 0.81 & 2.68 & 7.08 \\
\hline & 400 & 0.81 & 2.71 & 7.15 & 0.79 & 2.85 & 7.53 & 0.80 & 2.74 & 7.23 \\
\hline & 600 & 0.79 & 2.80 & 7.38 & 0.81 & 2.67 & 7.05 & 0.81 & 2.64 & 6.97 \\
\hline & 800 & 0.76 & 3.04 & 8.03 & 0.82 & 2.63 & 6.94 & 0.81 & 2.73 & 7.19 \\
\hline & 1000 & 0.78 & 2.88 & 7.59 & 0.86 & 2.31 & 6.11 & 0.81 & 2.71 & 7.15 \\
\hline \multirow[t]{6}{*}{$\mathrm{H}$} & 100 & 0.74 & 1.16 & 9.66 & 0.70 & 1.24 & 10.33 & 0.83 & 0.94 & 7.82 \\
\hline & 200 & 0.73 & 1.17 & 9.76 & 0.74 & 1.16 & 9.68 & 0.83 & 0.94 & 7.83 \\
\hline & 400 & 0.71 & 1.23 & 10.27 & 0.76 & 1.12 & 9.36 & 0.82 & 0.97 & 8.14 \\
\hline & 600 & 0.75 & 1.14 & 9.53 & 0.76 & 1.10 & 9.19 & 0.80 & 1.02 & 8.55 \\
\hline & 800 & 0.74 & 1.16 & 9.70 & 0.78 & 1.06 & 8.84 & 0.80 & 1.01 & 8.48 \\
\hline & 1000 & 0.70 & 1.23 & 10.31 & 0.78 & 1.05 & 8.80 & 0.81 & 0.99 & 8.24 \\
\hline
\end{tabular}
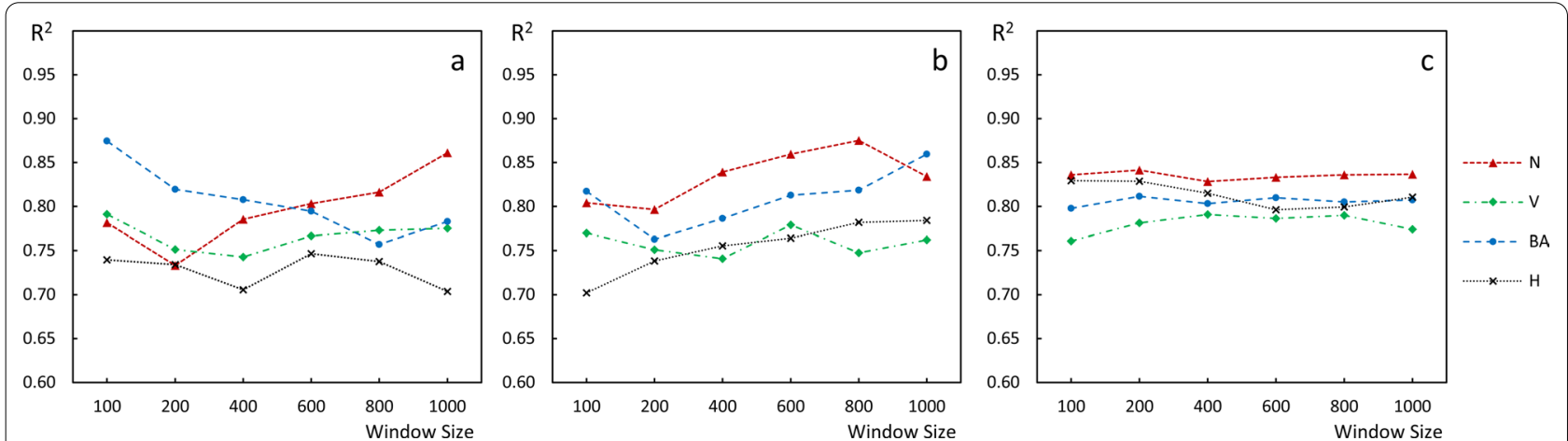

Fig. 3 Illustration of the window size effect on the prediction of the forest structural variables a WorldView-3, b Aerial image, $\mathbf{c} L i D A R$ (Black pine stands)

0.70 (for $100 \mathrm{~m}^{2}$ window size) and 0.88 (for $800 \mathrm{~m}^{2}$ window size) depending on the window size of digital aerial image. The model accuracy generally increased as the window size increased in aerial image. While the 1000 $\mathrm{m}^{2}$ window size performed better for BA $\left(R^{2}=0.86\right), 600$ $\mathrm{m}^{2}$ window size for $\mathrm{V}\left(R^{2}=0.78\right)$ and $800 \mathrm{~m}^{2}$ window size for $\mathrm{N}$ and $\mathrm{H}\left(R^{2}=0.88\right.$ and 0.78$)$ gave better results. The prediction accuracies ranged from 0.76 to 0.84 for LiDAR data depending on the window size. For all structural parameters, the estimation accuracies of the window sizes were almost the same. The $R^{2}$ values varied between 0.83 and 0.84 for $\mathrm{N}, 0.76$ and 0.79 for $\mathrm{V}, 0.80$ and 0.81 for $\mathrm{BA}$, and 0.80 and 0.83 for $\mathrm{H}$. Therefore, a significant 
difference between window sizes could not be determined to estimate the structural parameters for LiDAR data set.

Table 3 and Fig. 4 show the performance of different window sizes for estimation of structural parameters in the oak stands. The forest structural variables were estimated with $R^{2}$ ranging from 0.71 to 0.84 using features derived from WorldView-3 windows. The 100 and 600 $\mathrm{m}^{2}$ window sizes performed better for $\mathrm{V}\left(R^{2}=0.80\right)$. The $600 \mathrm{~m}^{2}$ window size provided the highest accuracy for $\mathrm{H}\left(R^{2}=0.85\right)$. Since $R^{2}$ values of window sizes were very close to each other in $\mathrm{N}(0.83$ and 0.85$)$ and BA (from 0.71 to 0.75 ), a significant difference could not be found between window sizes. In the digital aerial image, the 200 $\mathrm{m}^{2}$ window size for $\mathrm{V}$ and $\mathrm{BA}\left(R^{2}=0.79\right.$ and 0.75$)$ and $400 \mathrm{~m}^{2}$ for $\mathrm{H}\left(R^{2}=0.85\right)$ provided the highest prediction

Table 3 Prediction results of the forest structural variables according to different window sizes (Oak stands)

\begin{tabular}{|c|c|c|c|c|c|c|c|c|c|c|}
\hline \multirow{2}{*}{$\begin{array}{l}\text { Forest } \\
\text { variables }\end{array}$} & \multirow[t]{2}{*}{ Window size } & \multicolumn{3}{|c|}{ WorldView-3 } & \multicolumn{3}{|c|}{ Aerial image } & \multicolumn{3}{|c|}{ LiDAR } \\
\hline & & $R^{2}$ & RMSE & RMSE\% & $R^{2}$ & RMSE & RMSE\% & $R^{2}$ & RMSE & RMSE\% \\
\hline \multirow[t]{6}{*}{$\mathrm{N}$} & 100 & 0.84 & 110.55 & 9.92 & 0.90 & 87.67 & 7.87 & 0.89 & 91.34 & 8.20 \\
\hline & 200 & 0.84 & 112.58 & 10.10 & 0.90 & 89.56 & 8.04 & 0.90 & 87.54 & 7.85 \\
\hline & 400 & 0.83 & 114.38 & 10.26 & 0.92 & 79.37 & 7.12 & 0.89 & 90.91 & 8.16 \\
\hline & 600 & 0.84 & 110.47 & 9.91 & 0.92 & 81.14 & 7.28 & 0.90 & 90.13 & 8.09 \\
\hline & 800 & 0.84 & 111.87 & 10.04 & 0.91 & 83.60 & 7.50 & 0.89 & 92.92 & 8.34 \\
\hline & 1000 & 0.84 & 110.93 & 9.95 & 0.91 & 83.29 & 7.47 & 0.90 & 86.34 & 7.75 \\
\hline \multirow[t]{6}{*}{ V } & 100 & 0.77 & 23.79 & 10.66 & 0.72 & 26.27 & 11.77 & 0.87 & 17.61 & 7.89 \\
\hline & 200 & 0.78 & 23.00 & 10.31 & 0.79 & 22.61 & 10.13 & 0.87 & 17.98 & 8.06 \\
\hline & 400 & 0.80 & 22.23 & 9.96 & 0.76 & 24.07 & 10.78 & 0.86 & 18.64 & 8.35 \\
\hline & 600 & 0.80 & 22.21 & 9.95 & 0.74 & 25.16 & 11.27 & 0.87 & 17.94 & 8.04 \\
\hline & 800 & 0.76 & 24.10 & 10.80 & 0.73 & 25.89 & 11.60 & 0.86 & 18.64 & 8.35 \\
\hline & 1000 & 0.78 & 23.32 & 10.45 & 0.71 & 26.61 & 11.92 & 0.86 & 18.59 & 8.33 \\
\hline \multirow[t]{6}{*}{$\mathrm{BA}$} & 100 & 0.73 & 1.91 & 7.68 & 0.68 & 2.08 & 8.35 & 0.81 & 1.59 & 6.39 \\
\hline & 200 & 0.75 & 1.84 & 7.42 & 0.75 & 1.81 & 7.29 & 0.81 & 1.59 & 6.41 \\
\hline & 400 & 0.74 & 1.87 & 7.52 & 0.70 & 2.00 & 8.06 & 0.80 & 1.62 & 6.51 \\
\hline & 600 & 0.75 & 1.83 & 7.34 & 0.68 & 2.07 & 8.31 & 0.81 & 1.60 & 6.44 \\
\hline & 800 & 0.71 & 1.97 & 7.93 & 0.68 & 2.08 & 8.36 & 0.80 & 1.62 & 6.50 \\
\hline & 1000 & 0.75 & 1.83 & 7.35 & 0.67 & 2.09 & 8.41 & 0.80 & 1.62 & 6.53 \\
\hline \multirow[t]{6}{*}{$\mathrm{H}$} & 100 & 0.77 & 0.62 & 4.04 & 0.80 & 0.58 & 3.77 & 0.89 & 0.43 & 2.82 \\
\hline & 200 & 0.83 & 0.53 & 3.46 & 0.79 & 0.59 & 3.87 & 0.90 & 0.41 & 2.66 \\
\hline & 400 & 0.82 & 0.54 & 3.55 & 0.85 & 0.50 & 3.24 & 0.88 & 0.44 & 2.89 \\
\hline & 600 & 0.85 & 0.49 & 3.21 & 0.81 & 0.56 & 3.64 & 0.89 & 0.42 & 2.73 \\
\hline & 800 & 0.82 & 0.54 & 3.52 & 0.79 & 0.59 & 3.82 & 0.89 & 0.43 & 2.77 \\
\hline & 1000 & 0.81 & 0.56 & 3.66 & 0.77 & 0.62 & 4.07 & 0.90 & 0.42 & 2.72 \\
\hline
\end{tabular}
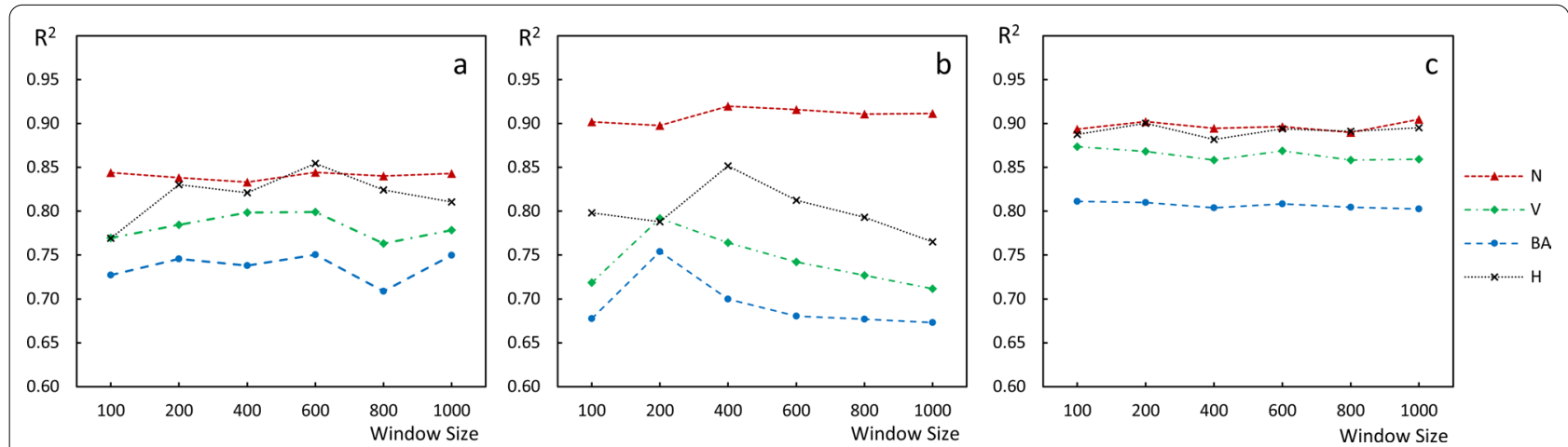

Fig. 4 Illustration of the window size effect on the prediction of the forest structural variables a WorldView-3, b Aerial image, c LiDAR (Oak stands) 
accuracy. On the other hand, no significant difference was found between window sizes for $\mathrm{N}$. However, the prediction accuracy provided by the window sizes of 400 $\mathrm{m}^{2}$ and $600 \mathrm{~m}^{2}$ is relatively higher than others. In LiDAR, the $R^{2}$ value of window sizes varied between 0.89 and 0.90 for $\mathrm{N}, 0.86$ and 0.87 for $\mathrm{V}, 0.80$ and 0.81 for BA, and 0.89 and 0.90 for $\mathrm{H}$. Therefore, a significant difference could not be determined between window sizes for all structural variables.

Table 4 shows the optimum window sizes for forest structural variables in the selected six window sizes. In our study, the window sizes explained by laser and image metrics of more than $50 \%$ of the variance was taken into consideration for optimal window size. Among these, the window size with the highest $R^{2}$ value was selected as the optimal window size. It appears that the determined optimal window size can be scaled up or down to fit forest canopy components. For example, the optimal window size was determined as $400 \mathrm{~m}^{2}$ to estimate the $\mathrm{V}$ using WorldView- 3 in the oak stands. However, $200 \mathrm{~m}^{2}$ and $600 \mathrm{~m}^{2}$ window sizes provided the same or close prediction accuracy. Similarly, optimal window size for estimating $\mathrm{N}$ from digital aerial image is $400 \mathrm{~m}^{2}$. Due to the same or close estimation accuracy, window sizes of $200 \mathrm{~m}^{2}$ and $600 \mathrm{~m}^{2}$ can also be selected optimally.

\section{Discussion}

This study compared the ability of window sizes to predict the forest structural variables using the remote sensing data. We first built our prediction models using both ground truth data set and remote sensing data sets. Using these models, N, V, BA and $\mathrm{H}$ were estimated for different window sizes in even-aged pure black pine and oak stands. A number of window size ranging from 100 to $1000 \mathrm{~m}^{2}$ were tested. Our assumption was that the window size has an effect on the prediction accuracy. This assumption was supported by our findings that the

Table 4 Optimum window sizes for forest structural variables

\begin{tabular}{|c|c|c|c|c|}
\hline & \multirow{2}{*}{$\begin{array}{l}\text { Forest } \\
\text { variables }\end{array}$} & \multicolumn{3}{|c|}{ Optimal window sizes $\left(\mathrm{m}^{2}\right)$} \\
\hline & & WorldView-3 & Aerial image & LiDAR \\
\hline \multirow[t]{4}{*}{ Black pine } & $\mathrm{N}$ & 1000 & 800 & $100-1000$ \\
\hline & V & 100 & 600 & $400-800$ \\
\hline & BA & 100 & 1000 & $100-1000$ \\
\hline & $\mathrm{H}$ & 600 & $800-1000$ & $100-200$ \\
\hline \multirow[t]{4}{*}{ Oak } & $\mathrm{N}$ & $100-1000$ & $400-600$ & $100-1000$ \\
\hline & V & $400-600$ & 200 & $100-1000$ \\
\hline & $\mathrm{BA}$ & $100-1000$ & 200 & $100-1000$ \\
\hline & $\mathrm{H}$ & 600 & 400 & $100-1000$ \\
\hline
\end{tabular}

prediction accuracy varies according to different window sizes.

In the WorldView-3 satellite image, significant differences were observed between the prediction accuracies of the image windows for forest structural variables. For each structural variable, all window sizes provided a coefficient of determination greater than 0.70. In the black pine stands, $R^{2}$ values calculated for the selected six window sizes showed that the $1000 \mathrm{~m}^{2}$ window size is more efficient than the other window sizes to estimate the $\mathrm{N}$. The $600 \mathrm{~m}^{2}$ window size is optimal for $\mathrm{H}$ and the $100 \mathrm{~m}^{2}$ window size is optimal for V and BA. In the case of oak stands, the $R^{2}$ values of each moving window size (from 100 to $1000 \mathrm{~m}^{2}$ ) were almost identical for $\mathrm{N}$ and BA. This indicates that there was little difference in significance level among the different window sizes. In this case, the appropriate window size can be determined as a size that minimizes a given cost function (Kayitakire et al. 2006) and match stand canopy components (Rich et al. 2010). The $R^{2}$ values of 400 and $600 \mathrm{~m}^{2}$ window sizes were identical for V. Therefore, both can be used as optimal window size to estimate the $\mathrm{V}$. In addition, the $600 \mathrm{~m}^{2}$ window sizes performed better to predict $\mathrm{H}$.

Overall, the performance of large window sizes from digital aerial image was better than small window sizes for estimating forest structural variables. In the black pine stands, the prediction accuracy increases as window size increases, and window sizes larger than $600 \mathrm{~m}^{2}$ are more efficient than other window sizes for estimation. $R^{2}$ values calculated for the selected six window sizes showed that the $800 \mathrm{~m}^{2}$ window size is optimal for $\mathrm{N}$, the $600 \mathrm{~m}^{2}$ window size is optimal for $\mathrm{V}$ and the $1000 \mathrm{~m}^{2}$ window size is optimal for BA. The 800 and $1000 \mathrm{~m}^{2}$ window sizes with same prediction accuracy obtained higher accuracy than smaller window sizes for $\mathrm{H}$. Therefore, one of these two sizes can be used as the optimal window size to estimate $\mathrm{H}$. The window size of $200 \mathrm{~m}^{2}$ seems optimal for estimating $\mathrm{V}$ and $\mathrm{BA}$ based on aerial image in the oak stands. While window sizes of 400 and $600 \mathrm{~m}^{2}$ are optimal for estimating $\mathrm{N}, 400 \mathrm{~m}^{2}$ window size is optimal for $\mathrm{H}$.

The prediction accuracy derived from leave-one-out cross-validation for forest structural variables showed that there is generally no significant difference among the different window sizes used for predicting in LiDAR data because the $R^{2}$ values of each window size were almost identical for all variables in the black pine and oak stands.

There are limited number of published studies on relationships between window size and forest structural variables. These studies used different remote sensing data, different reference data and different analysis techniques. Hence, it is difficult to compare the results directly. However, studies can be compared to some extent by means of 
changes in $R^{2}$ values, which are considered as indicators of relationship fittings (Castillo-Santiago et al. 2010). The differences with similar studies are probably due to differences in stand structures and tree species composition. Holopainen and Wang (1998) stated that the window size of $20 \times 20 \mathrm{~m}\left(400 \mathrm{~m}^{2}\right)$ is the near-optimal window size for feature extraction from aerial photograph in forest inventory. Kayitakire et al. (2006) reported that the optimum window size for density, height and basal area is $5 \times 5$ pixel, $15 \times 15$ pixel and $25 \times 25$ pixel, respectively. These window sizes provided the highest $R^{2}$ values. Steinmann et al. (2013) stated that the window size of $25 \times 25 \mathrm{~m}(625$ $\mathrm{m}^{2}$ ) is optimal for estimating the forest growing stock volume using LiDAR data and aerial images. Tonolli et al. (2011) tested different cell sizes (from 20 to $60 \mathrm{~m}$ ) to map the tree stem volume using LiDAR data, and it was determined that $40 \times 40 \mathrm{~m}$ cell size provided the highest $R^{2}$ value as optimal cell size. By contrary, we found that there is no significant difference among the different window sizes for predicting forest structural variables. Meng et al. (2016) used the spectral and texture features extracted from seven different window sizes to estimate the forest structure from the SPOT-5 satellite image. They revealed that the window size of $9 \times 9$ pixels is the optimum size for calculating texture statistics. Zhao et al. (2018) concluded that the optimal window size increases as the spatial resolution increases using QuickBird multispectral and panchromatic images. On the other hand, our study results revealed that a generalization cannot be made for LiDAR, WorldView-3 and digital aerial imagery. According to Günlü et al. (2021), the small window size for WorldView-2 did not improve the estimation result (except for the number of trees). It was emphasized that $17 \times 17,19 \times 19$ and $23 \times 23$ window sizes gave the best results. In our study, small window sizes generally yielded the best results for coniferous stands, except for the number of trees. Similarly, Zhou et al. (2020) found that smaller window sizes (such as $3 \times 3$ and $5 \times 5$ ) give better results overall.

As a result, the window size, which is used to calculate the reference laser and image metrics in prediction of forest structural variables based on remote sensing data, influences the prediction accuracy. The optimal window size varies according to remote sensing data, tree type composition and stand variable to be predicted. The optimal window size can be scaled up or down to fit forest canopy components (Rich et al. 2010).

\section{Conclusion}

This study explored the effect of window size on estimation of forest structural variables using airborne LiDAR, digital aerial image and WorldView-3 satellite data. The estimation models were created using ground truth data set and remote sensing data set in the black pine and oak stands, and estimation accuracies of stand variables such as stem number, volume, basal area and mean height were calculated for different window sizes. We compared the estimation accuracy for different moving window sizes ranging from 100 to $1000 \mathrm{~m}^{2}$ to find the optimal window size. In the digital aerial image and WorldView-3 satellite data, significant differences were observed between the prediction accuracies of the image windows for forest structural variables. However, in the LiDAR data, the prediction accuracies for each moving window size were almost identical. Therefore, there was no significant difference between different sizes. We invite other researchers to do similar studies using different remote sensing data in stands with different structure and species composition.

\section{Abbreviations}

BA: Basal area; DBH: Diameter at breast height; DTM: Digital terrain model; GLCM: Grey level co-occurrence matrix; GPS: Global positioning system; H: Mean height; N: Stem number; NDVI: Normalized Difference Vegetation Index; NPC: Normalized point cloud; TIN: Triangulated irregular networks; $R^{2}$ : Coefficient of determination; RF: Random forest; V: Volume.

\section{Acknowledgements}

LiDAR and WorldView-3 data used in this study were obtained from the project (the Project No 1170675) supported by The Scientific and Technological Research Council of Turkey (TÜBITAK). We would like to thank TÜBITAK. Furthermore, we would like to thank General Directorate of Forestry, Forest Management and Planning Department, which provided digital aerial images.

\section{Authors' contributions}

All authors contributed equally to this paper. Both authors read and approved the final manuscript.

Funding

Not applicable.

Availability of data and materials

All data and materials can be obtained by requesting from the author.

\section{Declarations}

Ethics approval and consent to participate Not applicable.

Consent for publication

Not applicable.

Competing interests

The authors declare that they have no competing interests.

Received: 25 June 2021 Accepted: 23 August 2021

Published online: 08 September 2021

\section{References}

Amini J, Sumantyo JTS (2009) Employing a method on SAR and optical images for forest biomass estimation. IEEE Trans Geosci Remote Sens 47:4020-4026 
Balenović I, Seletković A, Pernar R, Jazbec A (2015) Estimation of the mean tree height of forest stands by photogrammetric measurement using digital aerial images of high spatial resolution. Ann For Res 58:125-143

Breiman L (2001) Random forests. Mach Learn 45:5-32

Castillo-Santiago MA, Ricker M, de Jong BH (2010) Estimation of tropical forest structure from SPOT-5 satellite images. Int J Remote Sens 31:2767-2782

Cho MA, Skidmore AK, Sobhan I (2009) Mapping beech (Fagus sylvatica L.) forest structure with airborne hyperspectral imagery. Int J Appl Earth Obs 11:201-211. https://doi.org/10.1016/j.jag.2009.01.006

Gao X, Wen J, Zhang C (2019) An improved random forest algorithm for predicting employee turnover. Math Probl Eng 2019:4140707. https://doi. org/10.1155/2019/4140707

García M, Saatchi S, Ustin S, Balzter H (2018) Modelling forest canopy height by integrating airborne LiDAR samples with satellite Radar and multispectral imagery. Int J Appl Earth Obs Geoinf 66:159-173

Guan H, Li J, Chapman M, Deng F, Ji Z, Yang X (2013) Integration of orthoimagery and lidar data for object-based urban thematic mapping using random forests. Int J Remote Sens 34:5166-5186

Günlü A, Ercanlı I, Şenyurt M, Keleş S (2021) Estimation of some stand parameters from textural features from WorldView-2 satellite image using the artificial neural network and multiple regression methods: a case study from Turkey. Geocarto Int 36(8):918-935

Hájek F (2008) Process-based approach to automated classification of forest structures using medium format digital aerial photos and ancillary GIS information. Eur J Forest Res 127:115-124

Harralick RM, Shanmugam K, Dinstein I (1973) Textural features for images classification. IEEE Trans Syst Man Cybern SMC 6:610-621

Holopainen M, Wang G (1998) The calibration of digitized aerial photographs for forest stratification. Int J Remote Sens 19:677-696

Hu B, Li J, Jing L, Judah A (2014) Improving the efficiency and accuracy of individual tree crown delineation from high-density LiDAR data. Int J Appl Earth Obs Geoinf 2:145-155

Hyyppa HJ, Hyyppa JM (2001) Effects of stand size on the accuracy of remote sensing-based forest inventory. IEEE Trans Geosci Remote Sens 39:2613-2621

Iovan C, Boldo D, Cord M (2008) Detection, characterization, and modeling vegetation in urban areas from high-resolution aerial imagery. IEEE J Select Topics Appl Earth Observ Remote Sens 1:206-213

Joshi NP, Mitchard ET, Schumacher J, Johannsen VK, Saatchi S, Fensholt R (2015) L-band SAR backscatter related to forest cover, height and aboveground biomass at multiple spatial scales across Denmark. Remote Sens 7:4442-4472

Kanja K, Karahalil U, Çil B (2019) Modeling stand parameters for Pinus brutia (Ten.) using airborne LiDAR data: a case study in Bergama. J Appl Remote Sens 14(2):022205

Kaushal S, Baishya R (2021) Stand structure and species diversity regulate biomass carbon stock under major Central Himalayan forest types of India. Ecol Process 10:14

Kayitakire F, Hamel C, Defourny P (2006) Retrieving forest structure variables based on image texture analysis and IKONOS-2 imagery. Remote Sens Environ 102:390-401

Koch B, Straub C, Dees M, Wang Y, Weinacker H (2009) Airborne laser data for stand delineation and information extraction. Int J Remote Sens 30:935-963

Kwak DA, Lee WK, Lee JH, Biging GS, Gong P (2007) Detection of individual trees and estimation of tree height using LiDAR data. J For Res 12:425-434

Lee H, Slatton KC, Roth BE, Cropper WP Jr (2010) Adaptive clustering of airborne LiDAR data to segment individual tree crowns in managed pine forests. Int J Remote Sens 31:117-139

Liaw A, Wiener M (2002) Classification and regression by randomForest. R News 2:18-22

Lidar360 (2018) Lidar360 User Guide. GreenValley Int, California

Lim K, Treitz P, Wulder M, St-Onge B, Flood M (2003) LiDAR remote sensing of forest structure. Prog Phys Geogr 27(1):88-106

Maltamo M, Malinen J, Packalén P, Suvanto A, Kangas J (2006) Nonparametric estimation of stem volume using airborne laser scanning, aerial photography, and stand-register data. Can J Res 36:426-436

Meng J, Li S, Wang W, Liu Q, Xie S, Ma W (2016) Estimation of forest structural diversity using the spectral and textural information derived from SPOT-5 satellite images. Remote Sens 8:125
Morgan JL, Gergel SE (2010) Quantifying historic landscape heterogeneity from aerial photographs using object-based analysis. Landsc Ecol 25:985-998

Næsset E (2002) Predicting forest stand characteristics with airborne scanning laser using a practical two-stage procedure and field data. Remote Sens Environ 80:88-99

Ozdemir I, Donoghue DNM (2013) Modelling tree size diversity from airborne laser scanning using canopy height models with image texture measures. For Ecol Manage 295:28-37

Ozdemir I, Karnieli A (2011) Predicting forest structural parameters using the image texture derived from WorldView-2 multispectral imagery in a dryland forest, Israel. Int J Appl Earth Obs Geoinf 13:701-710

Ozkan UY, Demirel T (2018) Estimation of forest stand parameters by using the spectral and textural features derived from digital aerial images. Appl Ecol Environ Res 16:3043-3060

Ozkan UY, Ozdemir I, Saglam S, Yesil A, Demirel T (2016) Evaluating the woody species diversity by means of remotely sensed spectral and texture measures in the urban forests. J Indian Soc Remote Sens 44:687-697

Ozkan UY, Demirel T, Ozdemir I, Saglam S, Mert A (2020) Examining LiDARWorldView-3 data synergy to generate a detailed stand map in a mixed forest in the north-west of Turkey. Adv Space Res 65:2608-2621

Pascual C, García-Abril A, García-Montero LG, Martín-Fernández S, Cohen WB (2008) Object-based semi-automatic approach for forest structure characterization using lidar data in heterogeneous Pinus sylvestris stands. For Ecol Manage 255:3677-3685

PCl Geomatics (2017) Geomatica Help. PCI Geomatics, Ontario

Rich RL, Frelich L, Reich PB, Bauer ME (2010) Detecting wind disturbance severity and canopy heterogeneity in boreal forest by coupling highspatial resolution satellite imagery and field data. Remote Sens Environ 114:299-308

Robinson C, Saatchi S, Neumann M, Gillespie T (2013) Impacts of spatial variability on aboveground biomass estimation from L-band radar in a temperate forest. Remote Sens 5:1001-1023

Ruiz LA, Hermosilla T, Mauro F, Godino M (2014) Analysis of the influence of plot size and LiDAR density on forest structure attribute estimates. Forests 5:936-951

Shamsoddini A, Trinder JC, Turner R (2013) Pine plantation structure mapping using WorldView-2 multispectral image. Int J Remote Sens 34:3986-4007

Steinmann K, Mandallaz D, Ginzler C, Lanz A (2013) Small area estimations of proportion of forest and timber volume combining Lidar data and stereo aerial images with terrestrial data. Scand J For Res 28:373-385

Tonolli S, Dalponte M, Vescovo L, Rodeghiero M, Bruzzone L, Gianelle D (2011) Mapping and modeling forest tree volume using forest inventory and airborne laser scanning. Eur J For Res 130:569-577

Tuominen S, Pekkarinen A (2005) Performance of different spectral and textural aerial photograph features in multi-source forest inventory. Remote Sens Environ 94(2):256-268

Ustin SL, Middleton EM (2021) Current and near-term advances in Earth observation for ecological applications. Ecol Process 10:1

Zald HS, Ohmann JL, Roberts HM, Gregory MJ, Henderson EB, McGaughey RJ, Braaten J (2014) Influence of lidar, Landsat imagery, disturbance history, plot location accuracy, and plot size on accuracy of imputation maps of forest composition and structure. Remote Sens Environ 143:26-38

Zenner EK, Peck JE (2009) Characterizing structural conditions in mature managed red pine: spatial dependency of metrics and adequacy of plot size. For Ecol Manage 257:311-320

Zeybek M, Vatandaşlar C (2021) An automated approach for extracting forest inventory data from individual trees using a handheld mobile laser scanner. Croatian J For Eng 42(3):515-528

Zhao Q, Wang F, Zhao J, Zhou J, Yu S, Zhao Z (2018) Estimating forest canopy cover in black locust (Robinia pseudoacacia L.) plantations on the loess plateau using random forest. Forests 9:623

Zhou J, Zhou Z, Zhao Q, Han Z, Wang P, Xu J, Dian Y (2020) Evaluation of different algorithms for estimating the growing stock volume of Pinus massoniana plantations using spectral and spatial information from a SPOT6 image. Forests 11(5):540

\section{Publisher's Note}

Springer Nature remains neutral with regard to jurisdictional claims in published maps and institutional affiliations. 